\title{
Grouping Factor
}

National Cancer Institute

\section{Source}

National Cancer Institute. Grouping Factor. NCI Thesaurus. Code C61039.

A factor whose levels separate the sampling units into groups whereby no subject is exposed to more than one level of the factor. 